\title{
A Human Lymphoma Cell Line with Multiple Immunoglobulin Rearrangements
}

\author{
Hong Chang," Hans A. Messner," X.-H. Wang," Cassian Yee," L. Addy, ${ }^{\star}$ J. Meharchand, ${ }^{\star}$ and Mark D. Minden* \\ *Department of Medicine and Medical Biophysics, Ontario Cancer Institute/Princess Margaret Hospital, Toronto, Ontario M4X 1K9; \\ and ${ }^{\ddagger}$ Cytogenetics Laboratory, Wellesley Hospital, Toronto, Ontario M4X 1K9, Canada
}

\begin{abstract}
The development of a cell culture system efficient in the establishment of lymphoma cell lines has made it possible to dissect basic biological and molecular aspects of lymphoma cells. We have established a lymphoma cell line from a patient with B cell lymphoma. The cell line has a complex karyotype with translocations involving bands 8q24, 14q32, and 18q21. Molecular analysis revealed that the Myc gene was rearranged; we were unable to demonstrate rearrangement of the Bcl-2 gene. Evaluation of the structure of the heavy chain Ig genes revealed that the cell line carried the same rearrangements as the cells from which the cell line was derived. The pattern of rearrangement, however, was unusual in that there were at least four rearranged bands when DNA cut with HindIII was probed with a fragment of the heavy chain joining region. To further characterize the cell line, subclones were derived. Individual subclones had the same pattern of rearrangement as the parent cell line. The results of these studies provide evidence that multiple rearranged Ig genes may be present in a single clone of cells. ( $J$. Clin. Invest. 1992. 89:1014-1020.) Key words: cancer • chromosome translocation • hemopoiesis
\end{abstract}

\section{Introduction}

Malignant lymphoma is a heterogenous disease with regards to histology, immunological phenotypes, growth rate, clinical presentation, and response to therapy. In spite of recent advances in treatment, the overall prognosis of malignant lymphoma is still poor. Significant improvement in the treatment of lymphoma will likely depend upon greater understanding of the development, maintenance, and progression of the disease.

The use of molecular techniques makes it possible to explore genetic events associated with the development and progression of lymphoma. Korsmeyer et al. (1) first demonstrated the rearrangement of the human Ig genes in DNA from leukemic and lymphoma cells committed to B cell differentiation. The detection of the rearrangement of the Ig genes was not only an indication that the tumors were of the B cell lineage but also indicated that the tumors were of clonal origin, because in Southern blot analysis of a polyclonal population of $B$ cells one does not see distinct rearranged Ig genes (2). The original stud-

Address reprint requests to Dr. Mark D. Minden, Department of Medicine and Medical Biophysics, Ontario Cancer Institute/Princess Margaret Hospital, 500 Sherbourne Street, Toronto, ON M4X 1K9, Canada.

Received for publication 4 March 1991 and in revised form 22 October 1991

J. Clin. Invest.

(c) The American Society for Clinical Investigation, Inc.

0021-9738/92/03/1014/07 \$2.00

Volume 89, March 1992, 1014-1020 ies have been confirmed and extended by a large number of groups (2-5). In most cases only one or two rearranged bands are seen (1); however, in some cases three or more rearranged bands can be identified (6-9). Various explanations have been proposed; these range from the suggestion that all of the rearranged bands are present in all of the cells to the suggestion that the disease is in fact oligoclonal and that individual clones carry unique rearrangements. However, evidence to support these models has been circumstantial.

Recently we established a cell line, OCI-Ly 18, from the pleural fluid of a patient with malignant lymphoma. Cytogenetic analysis revealed multiple chromosomal abnormalities. Molecular studies of the Ig heavy chain joining $\left(\mathrm{J}_{\mathbf{H}}\right)$ region demonstrated the presence of several rearranged bands without a germline band; this was observed with three different restriction enzymes. In this paper we present the phenotypic, cytogenetic, and molecular characterization of OCI-LY 18 and its clonal isolates. Results from these studies indicate that in some cases more than two rearranged bands may all be present within the same clone.

\section{Methods}

Case history. A 56-yr-old man presented in January 1988 with weight loss, night sweats, and an abdominal mass. At laparotomy a large mass was found attached to the small and large bowel, possibly arising from the retroperitoneal area. A lymph node biopsy demonstrated infiltration of adipose tissue by large malignant cells with an irregular nuclear contour; prominent, sometimes multiple, nucleoli; and copious basophilic cytoplasm. A bone marrow biopsy was negative for tumor cells. On the basis of these observations and cytochemical and immunological characteristics (Table I), the patient was diagnosed as having a high grade non-Hodgkin's lymphoma of diffuse large cell immunoblastic type. Initial treatment was radiotherapy to the abdominal mass followed by combination chemotherapy consisting of cis-platinum, ara$\mathrm{C}$, VP16, and dexamethasone. This resulted in a short complete remission of 4 mo duration. At the time of relapse, a large malignant pleural effusion developed. Attempts at further chemotherapy were unsuccessful and the patient died of respiratory failure due to progressive disease $8 \mathrm{mo}$ after diagnosis.

Establishment of the cell line. Pleural fluid cells obtained at the time of autopsy were washed and placed into Iscove's modified Dulbecco's medium (IMDM) ${ }^{1}$ (Gibco Laboratories, Grand Island, NY), supplemented with $20 \%$ heparinized normal human plasma, and incubated at $37^{\circ} \mathrm{C}$ in humidified air containing $5 \% \mathrm{CO}_{2}(10)$. The cells continued to proliferate and after 3 mo were considered to be a cell line that morphologically resembled the malignant cells in the patient's pleural fluid. The cell line is referred to as OCI-Ly 18 , indicating that this is the 18th cell line generated in our laboratory from a patient with lymphoma.

Morphological and cytochemical studies. Cell morphology was examined on Wright-Giemsa-stained smears. Peroxidase and nonspecific esterase cytochemical stains were used.

1. Abbreviations used in this paper: $\mathrm{HC}$, heavy chain; IMDM, Iscove's modified Dulbecco's medium; $\mathbf{J}_{\mathrm{H}}$, Ig HC joining region; LC, light chain. 
Table I. Cell Surface Marker Profile of OCI-Ly 18

\begin{tabular}{llr}
\hline & Immunophenotype of OCI-Ly 18 \\
\hline CD10 & J5 & $85 \%$ \\
CD19 & B4 & $94 \%$ \\
CD20 & B1 & $92 \%$ \\
CD21 & B2 & $6 \%$ \\
CD23 & MHM6 & $1 \%$ \\
CD3 & OKT3 & $<1 \%$ \\
CD34 & MY10 & $<1 \%$ \\
Ig Surface & IgG & $<1 \%$ \\
& IgM & $84 \%$ \\
& IgD & $8 \%$ \\
& IgA & $15 \%$ \\
& $\kappa$ & $<1 \%$ \\
& $\lambda$ & $94 \%$ \\
Cytoplasmic & IgM & $90 \%$ \\
& TdT & Neg \\
Cytochemistry & PAS & Pos \\
& NSE & Neg \\
& Peroxidase & Neg \\
& Acid phosphatase & Pos \\
& &
\end{tabular}

Immunological studies. The presence of surface Ig was examined with FITC-conjugated polyvalent goat anti-human Ig (Tago Inc., Burlington, Ontario, Canada). Cytoplasmic Ig was detected with FITCconjugated goat anti-human $\mu$-chain after cytocentrifugation of the cells onto glass slides and fixation in $75 \%$ ethanol and $25 \%$ acetic acid (10). The mAbs used were reactive against the following cell surface antigens: CD19 (B4), CD20 (B1), CD 21 (B2), CD23 (MHM6), CD3 (OKT3), CD34 (My10) (Coulter Electronics Inc., Hialeah, FL). Cells were examined by fluorescent microscopy and by FACS ${ }^{\circledR}$.

Karyotype analysis. Cytogenetic study was performed in the cytogenetics laboratory at the Wellesley Hospital, University of Toronto. Cells were obtained from the cell line OCI-Ly 18.11 metaphases were studied for modal number of chromosomes and the presence of chromosome abnormalities. The karyotypes were determined by both direct microscopic analysis and photography.

Subclone analysis. Cells of the cell line were collected and plated in semisolid culture containing $0.9 \%$ methylcellulose, $30 \%$ heparinized normal human plasma, $5 \times 10^{-5} \mathrm{M} 2$-mercaptoethanol, and $10 \%$ of medium conditioned by PHA (HA-15; Wellcome, Montreal, Quebec, Canada)-stimulated leukocytes at a concentration of $1 \times 10^{3}$ cells $/ \mathrm{ml}$. After $10 \mathrm{~d}$, five colonies, each containing 10-50 cells, were randomly picked from culture by using micropipettes and were placed in individual flat-bottom microwells $(6 \mathrm{~mm})$ containing IMDM supplemented with $20 \%$ heparinized human plasma (10). After 2 wk, each cell clone was transferred to a $50-\mathrm{cm}^{3}$ flask and maintained indefinitely in suspension culture.

Southern blot analysis. High molecular weight DNA was extracted from the established cell line and five subclones. Control DNA for Ig rearrangement was obtained from a $T$ cell lymphoma cell line that had already been shown to have germline Ig genes. DNA was digested with appropriate enzymes according to the recommendation of the supplier, fractionated by electrophoresis on $0.8 \%$ agarose gels, transferred to Gene-screen Plus (DuPont Co., Wilmington, DE) hybridized, washed, and exposed to Kodak XAR film with an intensifying screen at $-70^{\circ} \mathrm{C}$ as previously described (11).

$R N A$ analysis. RNA was isolated from the OCI-Ly 18 cell line, separated on an agarose-formaldehyde gel, and transferred to Genescreen Plus as previously described (11).

Probes. The probes used in this study were a 3-kb EcoRI-HindIII fragment to the $\mathrm{J}_{\mathbf{H}}$ region of the heavy chain (HC) locus (kindly pro- vided by Dr. P. Leder) (1); a 1.4-kb EcoRI fragment containing the first two exons of the $\mathrm{C} \mu$ gene (kindly provided by Dr. P. Leder) (12); pFL1 and pFL2 (kindly provided by Dr. M. Cleary) to the major and minor breakpoint cluster regions, respectively, of the Bcl-2 locus on chromosome $18(13,14)$; a 1.4-kb Clal-EcoRI fragment containing the third coding exon of the c-MYC gene on chromosome 8 (kindly provided by Dr. R. Della Favera) (15); $\kappa$-constant genes ( $\mathrm{C}_{k}, 2.5$-kb embryonic EcoRI $C_{k}$-containing fragment) (16); $\lambda$-Ig genes (C- $\lambda, 0.8$-kb embryonic EcoRI-HindIII C- $\lambda$-containing fragment) (17); and the BamHI K fragment of EBV kindly provided by Dr. G. Miller (Yale University, New Haven, CT) (18). Probes were labeled by random priming with $\left[{ }^{32} \mathrm{P}\right] \mathrm{dCTP}$ to a specific activity of $>10^{8} \mathrm{cpm} / \mu \mathrm{g}$ (19).

\section{Results}

\section{Establishment of the OCI-Ly 18 cell line}

The cell line was established from the pleural fluid of a patient with high grade non-Hodgkin's immunoblastic type malignant lymphoma as described in Methods. The line has now been carried continuously for $>12$ mo in suspension culture of IMDM supplemented with $20 \%$ normal human plasma without the addition of growth factors. The doubling time of the cell line is $36 \mathrm{~h}$; cells grow exponentially between 0.4 and $1.2 \times 10^{6}$ cells $/ \mathrm{ml}$. After $12 \mathrm{mo}$ in culture, the morphology of the cells of the parent cell line and five subclones still resembles that of the cells before culturing: cells are of large cell size, with high nuclear-to-cytoplasm ratio, basophilic cytoplasm without granules, and one or more nucleolus.

\section{Immunological phenotype}

As shown in Table I, IgM and Ig light chain $\lambda$ are expressed on the majority of the cells. Strong positive reactions are observed with antibodies directed against CD 19 (B4), CD 20 (B1), HLA$\mathrm{DR}$ antigens, and CD 10. The cells do not react with antibodies specific for the $\mathrm{T}$ cell surface antigen $\mathrm{CD} 3$.

\section{Karyotype analysis}

Cytogenetic analysis of the parent cell line and the subclones were similar; a representative karyotype is shown in Fig. 1. The modal number of chromosomes was 52 in 11 metaphases. There was a three-way translocation involving chromosomes 8 , 14 , and 14. An idiogram detailing the breakpoints is shown in Fig. 2: der 8 with a break at band q24 on chromosome 8 and the distal end of chromosome 14, band q32 to ter added to the chromosome; der 14 with a break at band $\mathrm{q} 32$ and the distal end of chromosome 18 from band q21 to ter added to the chromosome; and der 18 with a break on chromosome 18 at band q21 and the distal end of chromosome 8, band q24 to ter added to the chromosome. In addition there was loss of the $\mathrm{Y}$ chromosome; additional chromosomes $(+7,+9,+18,+18,+20$, $+21)$ were seen. There was also an $\mathrm{i}(17 \mathrm{q})$ and an insertion in chromosome 12 band q13.

\section{Molecular analyses}

$E B V$ analysis. Southern blots of DNA from the parent cell line and the subclones digested with EcoRI were probed for the presence of EBV. The probe did not detect the presence of EBV in the cell line, whereas a cell line known to contain the EBV genome was positive (data not shown).

Ig analysis. To determine the structure of the Ig genes, Southern blot analysis was performed on DNA cut with EcoRI, HindIII, or BamHI from the fresh pleural fluid cells, the parent cell line, and each of the five clones, with probes for $\mathrm{C}_{\mu}, \mathrm{J}_{\mathrm{H}}, \mathrm{C}_{\kappa}$, 


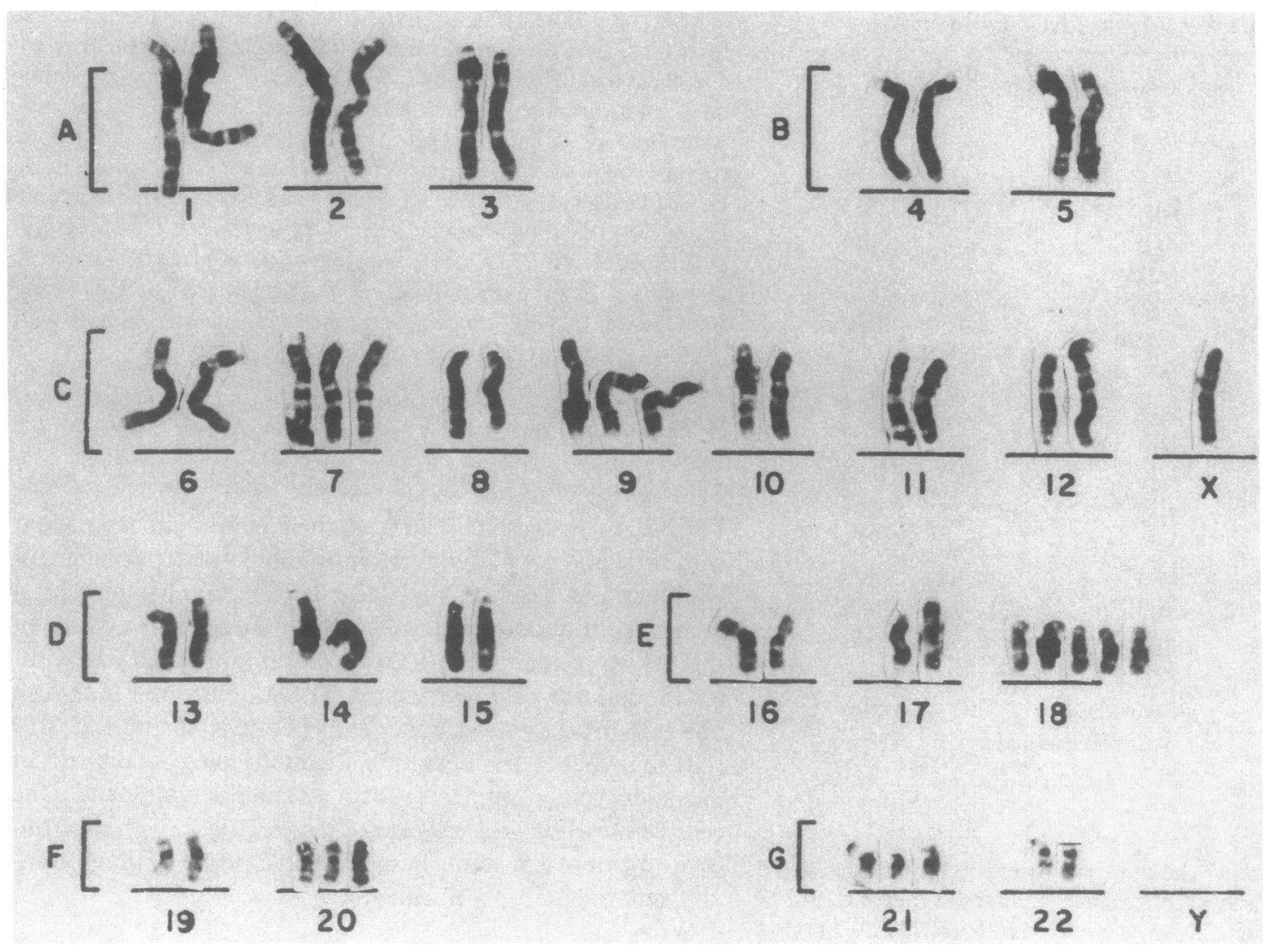

Figure 1. Karyotype of cell line OCI-Ly $18 ; 52, \mathrm{X},-? \mathrm{Y},+7, \mathrm{t}(8 ; 18 ; 14)(\mathrm{q} 24.1 ; \mathrm{q} 21.1 ; \mathrm{q} 32.2),+9$,ins(12;?)(q13;?),i(17q),+18,+18,+der(18)t(8;18) $(\mathrm{q} 24.1 ; \mathrm{q} 21.2),+20+21$.

and C $\lambda$. Fig. 3 is a schematic diagram of the Ig HC locus showing the sites at which restriction enzymes cut the DNA and the regions from which some of the probes were isolated. DNA digested with EcoRI and probed with the $\mathrm{J}_{\mathrm{h}}$ fragment showed five rearranged bands of 20, 8, 6, 4, and $3.5 \mathrm{~kb}$ (Fig. $4 A$ ); HindIII digests probed with $\mathrm{J}_{\mathrm{h}}$ yielded four rearranged bands of $8.5,6.5,4.4$, and $3.5 \mathrm{~kb}$ (the intensity of the $3.5-\mathrm{kb}$ band suggests that it might represent a doublet; Fig. $4 \mathrm{~B}$ ). A germline band was not observed in any of the samples. The same blots were reprobed with a fragment of the $C \mu$ region of the Ig locus. The Southern blot of EcoRI-digested DNA did not show any rearranged bands (Fig. $4 \mathrm{C}$ ), whereas HindIII- or BamHI-cut DNA examined with the same probe yielded three rearranged bands (Fig. $4 D$ and data not shown). In the HindIII-digested DNA the rearranged bands were of 9,8 , and $6.6 \mathrm{~kb}$. No germline bands were observed in the HindIII- or BamHI-digested samples. The $C_{\kappa}$ genes were deleted and a rearranged $C \lambda$ chain gene was observed (data not shown). The above results were observed regardless of whether DNA was from the pleural fluid cells, the parental cell line, or the subclones.

The presence of chromosome translocations involving bands $8 \mathrm{q} 24,14 \mathrm{q} 32$, and $18 \mathrm{q} 21$ suggested that some of the rearranged bands might be due to chromosome translocations between Ig on chromosome 14 and the $\mathrm{Myc}$ and $\mathrm{Bcl}-2$ genes on chromosomes 8 and 18, respectively. Southern blot analysis of the Myc gene revealed a rearranged and a germline band (Fig. 5 ), whereas analysis of the Bcl-2 locus with probes to the major (pFL1) and minor ( $p F L 2)$ breakpoint region did not show any rearrangement; the enzymes used in this analysis were EcoRI,
BamHI, and HindIII. RNA blot analysis revealed expression of both the c-Myc and the Bcl-2 genes (data not shown).

\section{Discussion}

A cell culture system is available that facilitates the proliferation and maintenance of a select group of malignant lymphoma cells. This technology was particularly useful in the investigations of a patient with malignant lymphoma that presented with a number of cytogenetic abnormalities and showed multiple rearrangements in the $\mathrm{J}_{\mathbf{H}}$ region.

The detailed cytogenetic and molecular analysis of OCI-Ly 18 revealed chromosome translocations involving the region of the MYC protooncogene on chromosome 8, the Ig HC locus on chromosome 14, and the region of the Bcl-2 gene on chromosome 18. Molecular analysis confirmed rearrangement and expression of the MYC gene. Southern blot analysis of the Bcl2 locus with two probes to the major and minor breakpoint cluster region of Bcl-2 did not identify any rearrangement; analysis of RNA from the cell line did indicate expression of the Bcl-2 gene. The probes used in the Southern blot analysis detect most translocations of Bcl-2 $(4,13,14)$; however, translocations occurring 5 ' of the Bcl-2 gene would be missed with the combinations of restriction enzymes and probes used in this study $(13,20)$.

The finding of cell lines like OCI-LY 18 with chromosome translocations involving bands $8 \mathrm{q} 24,14 \mathrm{q} 32$, and $18 \mathrm{q} 21$ have been described (21-24). In the cell line 380 , the translocations 
8

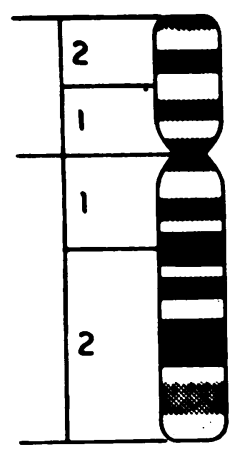

14

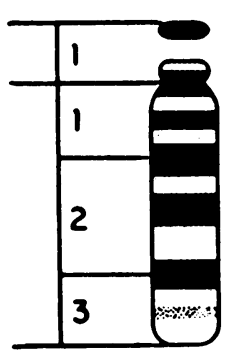

18

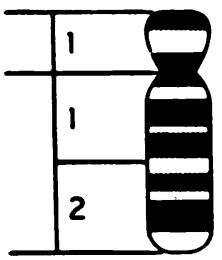

der 8

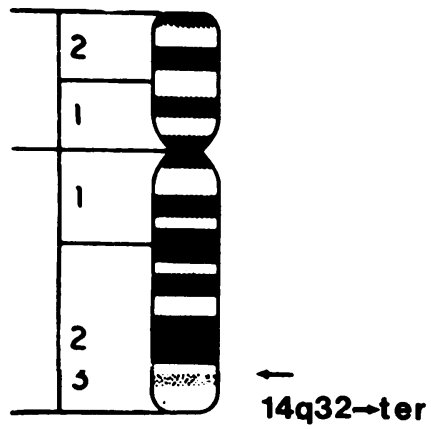

der 14

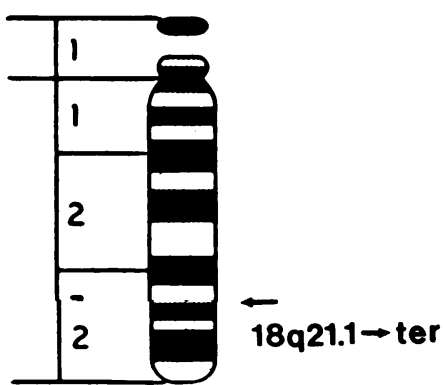

Figure 2. Idiogram demonstrating the $\mathrm{t}(8 ; 14 ; 18)(8 \mathrm{pter} \rightarrow 8 \mathrm{q} 24::$ 14 q32 $\rightarrow$ 14qter; 14pter $\rightarrow 14 q 32:: 18 q 21 \rightarrow 18 q$ ter; 18 pter $\rightarrow 18$ q21:: $8 \mathrm{q} 24 \rightarrow 8 \mathrm{qter})$.

involve both chromosomes 14; one of the translocations is a $t(14 ; 18)(q 32 ; 18 q 21)$ and the other a $t(8 ; 14)(q 24 ; q 32)$. Pegoraro et al. $(21)$ postulated that the $t(14 ; 18)$ occurred first and at some later time the $t(8 ; 14)$, involving the second chromosome 14 , occurred. As would be expected from the sites of translocation, the cells do not express either surface or cytoplasmic Ig (21). A second cell line with chromosome translocations involving $8 \mathrm{q} 24,14 \mathrm{q} 32$, and $18 \mathrm{q} 21$ is SU-DUL5; in this case there is a complex three-way translocation represented as $($ ter::8p23 $\rightarrow 8 \mathrm{q} 24:: 18 \mathrm{q} 21 \rightarrow 18 \mathrm{qter} ; 14 \mathrm{pter} \rightarrow 14 \mathrm{q} 32:: 18 \mathrm{q} 1 \rightarrow$ $18 \mathrm{q} 21:: 8 \mathrm{q} 24 \rightarrow 8 \mathrm{qter}, 18 \mathrm{pter} \rightarrow 18 \mathrm{q} 21:: 14 \mathrm{q} 32 \rightarrow$ 14qter). In SUDUL5 it is likely that a $t(14 ; 18)$ was followed by a $t(8 ;$ der 14$)$. In this cell line there is no expression of $\mathrm{Bcl}-2$, as the second translocation disrupted the gene (25). A third cell line KHM2B contains a $t(8 ; 14)(q 24 ; q 32)$ and $t(14 ; 18)(q 32 ; q 21)$. Unlike the other two cell lines, KHM-2B cells express RNA for Myc and $\mathrm{Bcl}-2$ and have surface IgM. As both chromosome 14's are affected in this cell line, it is postulated that the $t(8 ; 14)$ occurred in such a manner that the breakpoint in the Ig heavy chain locus is distal to $\mathrm{C} \mu$; this would account for the production of IgM (22). The cell line OCI-LY 18 is similar to these other cell lines in that it also contains chromosome translocations involving chromosomes 8,14 , and 18; however, the translocations differ from those previously described, as chromosome 8 sequences are attached to the der 18 chromosome. It has been suggested that the development of cells carrying such translocations occurs in a stepwise manner with the $t(14 ; 18)$ preceding the translocation of c-Myc sequences (21). For OCILY 18 , this is likely the case, with a possible sequence of events being first a $t(14 ; 18)(\mathrm{q} 32 ; \mathrm{q} 21)$ followed by a second translocation $\mathrm{t}(8 ;$ der18)(q24;q21). This could account for the simultaneous expression of Myc and Bcl-2 RNA and IgM protein in the cell line.

A second unusual feature in this $\operatorname{IgM} \lambda$-producing cell line was the pattern of rearrangement of the $\mathrm{J}_{\mathrm{H}}$ and $\mathrm{C} \mu$ regions; in both cases more than two rearranged fragments were observed. Multiple rearrangements of the Ig $\mathrm{HC}$ locus have been reported $(6-9,26-28)$; however, unique in this instance was the finding that the same pattern of rearrangement could be found in a cell line derived from the patient and five out of five clonal isolates derived from the cell line. By using a probe to the $J_{H}$ region, five rearranged bands were seen in DNA cut with EcoRI and four rearranged bands were seen in DNA cut with HindIII, although one of the bands had an increased intensity, suggesting that it was a doublet; no germline bands were seen with these combinations of restriction enzyme and probe. With the restriction enzymes BamHI or HindIII and a $\mathrm{C} \mu$ probe, three rearranged bands were seen; the intensity of these bands was about equal; again no germline band was seen with these combinations of restriction enzyme and probe. These results suggest that there are more than two copies of the Ig locus in an individual cell. This is in contrast to the cytogenetic analysis, which revealed only two recognizable chromosome 14's; however, the aneuploid nature of the cell with multiple abnormalities, including extra copies of chromosomes $7,9,18$, and der 18 as well as a region of insertion on chromosome 12 , makes precise cytogenetic definition difficult; and a duplication of the Ig-bearing region of chromosome 14 could be missed.

The finding of five rearranged bands with HindIII and the $\mathrm{J}_{\mathrm{H}}$ probe suggests that there are five copies of the Ig locus in the cell, whereas the same DNA probed with a $\mathrm{C} \mu$ fragment suggests that there are only three copies of the Ig locus in the cell. This discrepancy could be accounted for if some of the translocations observed in the cell occurred within the $\mathrm{J}_{\mathrm{H}}$ region cov-

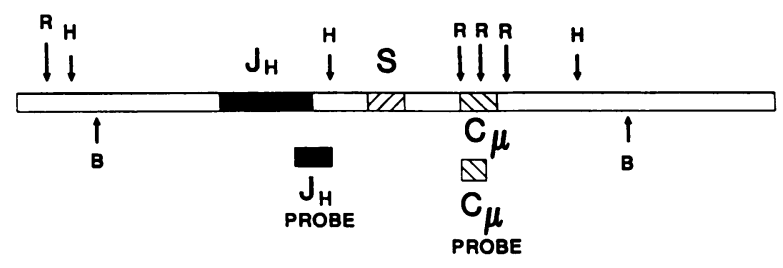

Figure 3. Map of the Ig HC locus in the region containing the joining $\left(\mathrm{J}_{\mathrm{H}}\right)$, switch $\left(\mathrm{S}_{\mathrm{H}}\right)$, and $\mu$ constant regions $\left(\mathrm{C}_{\mathrm{H}}\right)$. The restriction enzyme sites are shown $\mathrm{H}$, HindIII; $\mathrm{B}, \mathrm{BamH} 1$; and $\mathrm{R}$, EcoRI. The region to which the $J_{H}$ probe hybridizes is shown by $m$, and the region to which

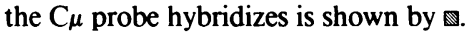



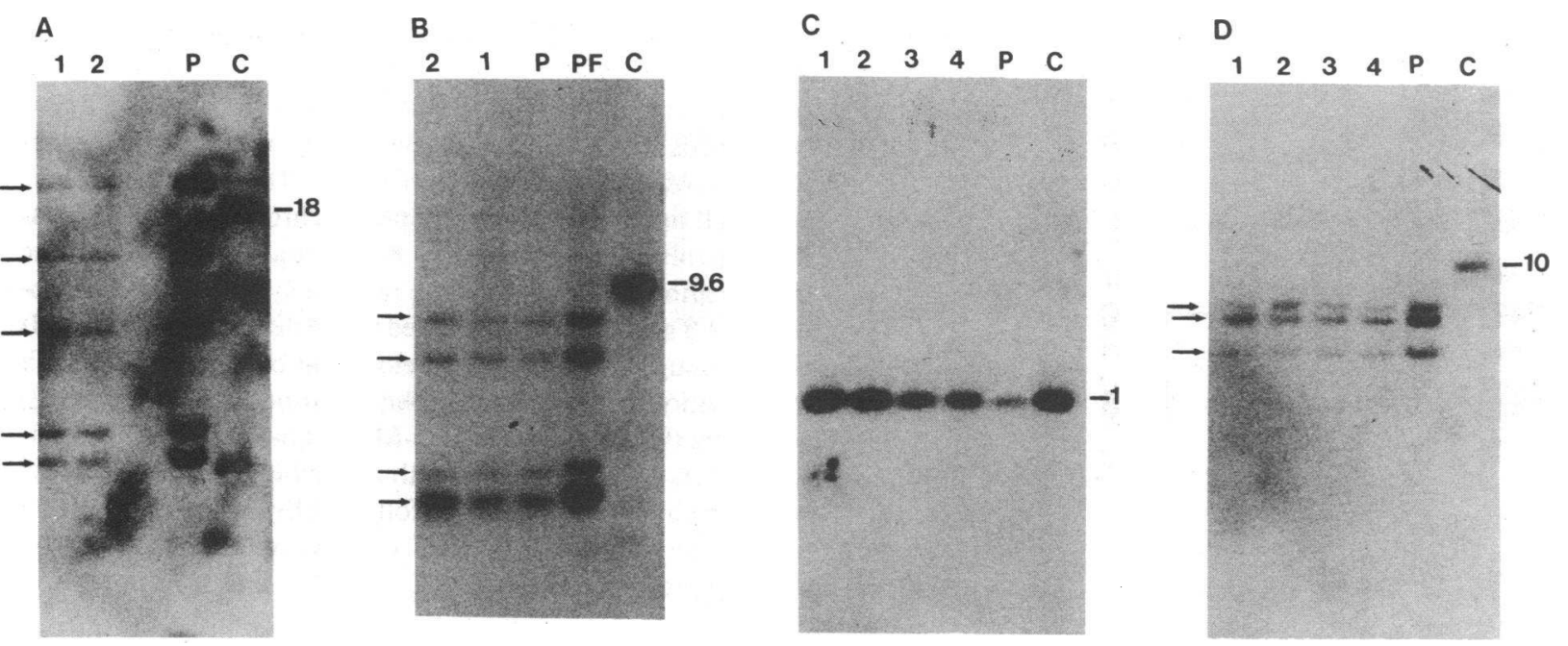

Figure 4. This figure demonstrates the pattern of rearrangement of the HC J region and the $\mu$ constant region present in the parental cell line and subclones of OCI-Ly 18. $(A)$ Southern blot demonstrating the pattern of rearrangement of DNA cut with the restriction enzyme EcoRI and probed with the $J_{H}$ probe. $C$ is control DNA, $P$ is DNA from parent cell line, and 1 and 2 are DNA from subclones 1 and 2 . The molecular weight in $\mathrm{kb}$ of the germline band is indicated on the right and the rearranged bands are indicated by arrows on the left. $(B)$ Southern blot demonstrating the pattern of rearrangement of DNA cut with the restriction enzyme HindIII and probed with the $J_{H}$ probe. PF is DNA extracted from cells present in the pleural fluid from the patient. The molecular weight in $\mathrm{kb}$ is indicated on the right. $(C)$ Southern blot of DNA digested with EcoRI and probed with a $\mu \mathrm{HC}$ constant region probe. The molecular weight of the resulting fragment in kb is shown on the right. 1-4 are DNA from subclones 1-4. (D) Southern blot of DNA digested with HindIII and probed with a $\mu$ HC constant region probe. The molecular weight of the germ line band in $\mathbf{k b}$ is shown on the right. The rearranged bands are indicated by arrows on the lift.

ered by that probe; this is the usual site for translocations involving the Bcl-2 locus (14). A similar explanation would not account for the three copies of $\mathrm{C} \mu$ present in the cell line, as Southern blots of EcoRI-digested DNA provide no evidence for a rearrangement occurring within the region covered by the $\mathrm{C} \mu$ probe.

The absence of a germline $\mathrm{C} \mu$ fragment in HindIII-digested DNA is not compatible with the production of IgM because, during the process of Ig rearrangement involving the $\mathrm{V}, \mathrm{D}$, and $\mathrm{J}$ segments, the HindIII fragment containing the $\mathrm{J}$ region but not the $\mathrm{C} \mu$ region is altered in size (Fig. 3). The lack of a germline-sized $\mathrm{C} \mu$ HindIII fragment and the continued expression

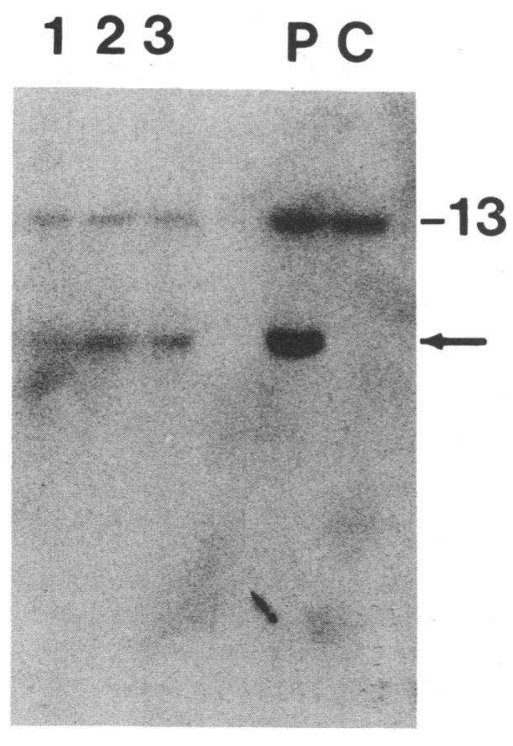

Figure 5. Southern blot of DNA cut with EcoRI and probed with the Myc probe. The size of the germline band in $\mathrm{kb}$ is indicated on the right and the position of the rearranged band is indicated by the arrow. Abbreviations same as in Fig. 4.

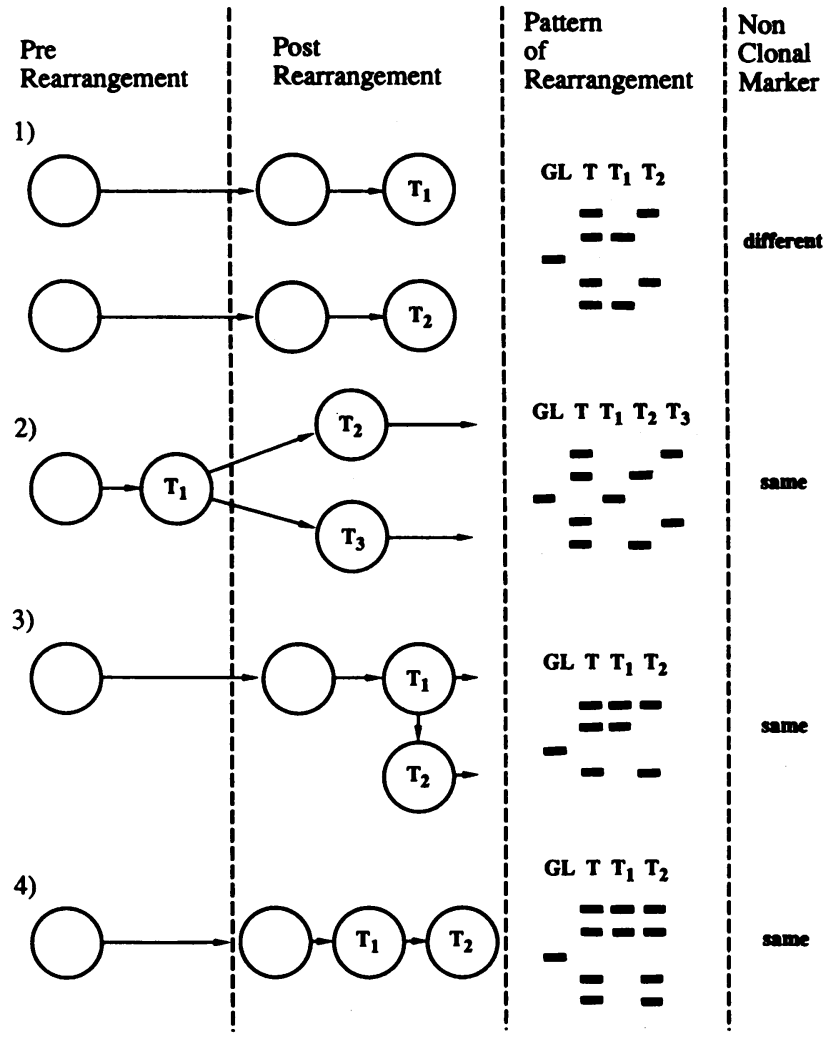

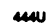

Figure 6. A schematic diagram illustrating the different ways in which more than two rearranged bands might be found in a sample. Each of the models is described in the discussion. GL, germ line; $T$, primary tumor in patient; $T_{1}, T_{2}$, and $T_{3}$, subclones $1-3$ of tumor, respectively. 
of IgM may be explained if a masked chromosome translocation occurred $3^{\prime}$ of $\mathrm{C} \mu$. Another possibility is the presence of an inherited or acquired restriction fragment-length polymorphism in the patient's DNA; unfortunately no nontumor DNA is available from the patient to test the latter possibility. To fully understand the molecular events that have occurred in this cell line and the involvement of the Ig, Myc, and Bcl-2 genes, further analysis (including in situ hybridization to metaphase chromosomes; Southern blot analysis with more defined probes; and, finally, cloning and sequencing of individual rearranged bands) will be necessary.

As mentioned above, multiple rearrangements have been noted previously in patient samples and have led to speculations concerning their origin and role in the evolution of the lymphomatous process. In most of the previous studies, information regarding gene rearrangement was obtained by Southern blot assessment of DNA prepared from involved lymph nodes, usually without cell separation. Based on these data, it was proposed that the disease in these particular patients was of oligoclonal origin; however, in the present case we present unambiguous proof that a single cell can contain multiple rearranged Ig genes. There are several models that may account for the presence of multiple rearranged bands; four possible models are described below and depicted in Fig. 6 .

Model 1. Several independent clones. In this model, the lymphoma arises in cells that are independent of each other. In such a case one would find that the observed rearranged bands account for the total pattern contributed by a small number of unique lymphoma clones. If isolated, each clone should show a unique pattern of rearrangement. An example of this is Richter's syndrome, for which a number of investigators have demonstrated that the pattern of rearrangement of the chronic lymphocytic leukemia population and the lymphoma clone are quite distinct $(29,30)$. A second example of this is that of EBVinduced proliferative disease occurring after cardiac transplantation $(31,32)$.

Model 2. Malignant transformation occurring before $H C$ and light chain $(L C)$ gene rearrangement. In this model, a genetic change in a lymphoid progenitor cell that enhances the probability for malignant transformation of this cell and its progeny occurs before $\mathrm{HC}$ gene rearrangement; each malignant clone that subsequently develops would then carry different patterns of rearranged genes. As in model 1 , the pattern of rearranged genes would be a summation of a number of malignant clones. One could distinguish between models 1 and 2 by using an additional clonal marker that was independent of the Ig region. For example, in a female the methylation pattern of the hypoxanthine phosphoribosyltransferase gene could be determined (33). In model 1 different clones would have different patterns of methylation, whereas in model 2 the same methylation pattern would be seen. There is no clear example of this in human disease; however, in an Abelson virus mouse model of leukemia, evidence for model 2 has been observed (34). In this case a cell line, 22D6, was derived in which all of the cells had the same integration site of the virus; however, there were multiple Ig HC rearrangements seen in the uncloned sample. Clonal isolates of 22D6 revealed only one or two rearranged bands that could be identified in the parent population. A variation of this model is that a genetic change occurs at the time of or after $\mathrm{HC}$ rearrangement and predisposes the progeny of this cell to malignant transformation. In such a case the malignant clones would have the same $\mathrm{HC}$ rearrangement but different
LC rearrangements. Two examples of this model have been reported $(9,35)$.

Model 3. Malignant transformation occurring after $\mathrm{HC}$ and $L C$ rearrangement. In this model, point mutations or additional rearrangements occur during the expansion of a clone of already transformed lymphoma cells. These changes would result in a new but related clone of cells that can coexist with the original clone of cells. Individual clones show either the original or the subsequent patterns that would sum to give the pattern of the overall population. There are several examples of this occurring in human disease (36-38). For example, Levy et al. (36) identified patients in whom lymphoma cells all react with an antiallotype antibody but only a subset of cells reacts with an antiidiotype antibody raised against the patients' lymphoma cells. The lack of reactivity with the antiidiotype antibody has been shown to be due to mutations in the Ig genes of the lymphoma cells (36).

Model 4. All rearranged bands are present in all cells of one clone. In this model, a committed B cell undergoes malignant transformation; during the growth of the malignant clone, additional genetic changes occur in cells, such as chromosomal translocation, chromosomal duplication, and further gene rearrangements. As a result of an acquired growth advantage, there is clonal succession. In this model a single clone exists and contains all of the rearranged bands present in the bulk population. The case described here provides firm evidence for this model.

In summary, the studies of this unique cell line illustrate the utility of immunological, cytogenetic, and molecular analyses in identifying complex genetic changes in human lymphoma. Our studies clearly show that complex changes with multiple rearrangements of $\mathrm{Ig} \mathrm{HC}$ genes may occur in a single clone of cells.

\section{Acknowledgments}

We thank Dr. I Dube for reviewing the cytogenetic studies.

This work was supported by grants from the National Cancer Institute of Canada, the Medical Research Council of Canada, and the Leukemia Research Fund, Canada.

\section{References}

1. Korsmeyer, S. J., P. A. Hieter, J. V. Ravetch, D. G. Poplack, T. A. Waldmann, and P. Leder. 1981. Developmental hierarchy of immunoglobulin gene rearrangements in human leukemic pre-B-cells. Proc. Natl. Acad. Sci. USA. 78:7096-7100.

2. Cleary, M. L., J. Chao, R. Warnke, and J. Sklar. 1984. Immunoglobulin gene rearrangement as a diagnostic criterion of B-cell lymphoma. Proc. Natl. Acad. Sci. USA. 81:593-597.

3. Arnold, A., J. Cossman, A. Bakhshi, E. S. Jaffe, T. A. Waldmann, and S. J. Korsmeyer. 1983. Immunoglobulin-gene rearrangements as unique clonal markers in human lymphoid neoplasms. N. Engl. J. Med. 309:1591-1599.

4. Cleary, M. L., N. Galili, and J. Sklar. 1986. Detection of a second $t(14 ; 18)$ breakpoint cluster region in human follicular lymphomas. J. Exp. Med. 164:315320.

5. Korsmeyer, S. J., A. Arnold, A. Bakhshi, J. V. Ravetch, U. Siebenlist, P. A. Hieter, S. O. Sharrow, and T. W. LeBien. 1983. Immunoglobulin gene rearrangement and cell surface antigen expression in acute lymphocytic leukemias of $T$ cell and B cell precursor origins. J. Clin. Invest. 71:301-313.

6. Kitchingman, G. R., J. Mirro, S. Stass, U. Rovigatti, S. L. Melvin, D. L. Williams, S. C. Raimondi, and S. B. Murphy. 1986. Biologic and prognostic significance of the presence of more than two $\mu$ heavy-chain genes in childhood acute lymphoblastic leukemia of B precursor cell origin. Blood. 67:698-703.

7. Foa, R., N. Migone, M. Saitta, M. T. Fierro, M. C. Giubellino, P. Lusso, L. Cordero di Montezemolo, and R. Miniero. 1984. Different stages of B cell differentiation in non-T acute lymphoblastic leukemia. J. Clin. Invest. 74:1756-1763.

8. Bertolli, L. F., H. Kubagawa, G. V. Borzillo, P. D. Burrows, M. T. 
Schreeder, A. J. Carroll, and M. D. Cooper. 1988. Bone marrow origin of a B-cell lymphoma. Blood. 72:94-101.

9. Sklar, J., M. L. Cleary, K. Thielemans, J. Gralow, R. Warnke, and R. Levy. 1984. Biclonal B cell lymphoma. N. Engl. J. Med. 311:20-27.

10. Tweeddale, M. E., B. J. Lim, N. Jamal, J. Robinson, J. Zalcberg, G. Lockwood, M. D. Minden, and H. A. Messner. 1987. The presence of clonogenic cells in high grade malignant lymphoma: a prognostic factor. Blood. 69:13071314.

11. Yee, C., A. Biondi, H.-H. Wang, N. N. Iscove, J. de Sousa, L. A. Aarden, G. G. Wong, S. D. Clark, H. A. Messner, and M. D. Minden. 1989. A possible autocrine role for interleukin-6 in two lymphoma cell lines. Blood. 74:798-804.

12. Ravetch, J., U. Siebenlist, S. Korsmeyer, T. Waldmann, and P. Leder. 1981. Structure of the human immunoglobulin $\mu$ locus: characterization of embryonic and rearranged J and D genes. Cell. 27:583-591.

13. Weiss, L. M., R. A. Warnke, J. SKlar, and M. L. Cleary. 1987. Molecular analysis of the $t(14 ; 18)$ chromosomal translocation in malignant lymphomas. $N$ Engl. J. Med. 317:1185-1189.

14. Cleary, M. L., and J. Sklar. 1985. Nucleotide sequence of a $t(14 ; 18)$ chromosomal breakpoint in follicular lymphoma and demonstration of a breakpointcluster region near a transcriptionally active locus on chromosome 18. Proc. Natl. Acad. Sci. USA. 82:7439-7443.

15. Dalla-Favera, R., E. P. Gelmann, S. Marinotti, G. Franchini, T. S. Papas, R. C. Gallo, and F. Wong-Staal. 1982. Cloning and characterization of different human sequences related to onc gene (v-MYC) of avian myelocytomatosis virus (MC29). Proc. Natl. Acad. Sci. USA. 79:6497-6501.

16. Hieter, P., J. Maizel, and P. Leder. 1982. Evolution of human immunoglobulin kappa J region genes. J. Biol. Chem. 257:1516-1522.

17. Hieter, P. A., G. F. Hollis, S. J. Korsmeyer, T. A. Waldmann, and P. Leder. 1981. Clustered arrangement of the immunoglobulin lambda constant region genes in man. Nature (Lond.). 294:536-540.

18. Andiman, W., L. Gradoviller, L. Heston, R. Neydroff, M. E. Savage, G. Kitchingam, D. Shedd, and G. Miller. 1983. Use of cloned probes to detect Epstein-Barr viral DNA in tissue of patients with neoplastic and lymphoproliferative diseases. J. Infect. Dis. 148:967-977.

19. Feinberg, A. P., and B. Vogelstein. 1983. A technique for radiolabeling DNA restriction endonuclease fragments to high specific activity. Anal. Biochem. 132:6-13.

20. Adachi, M., A. Tefferi, P. Greipp, T. Kipps, and Y. Tsujimoto. 1990 Preferential linkage of BCL-2 to immunoglobulin light chain gene in chronic lymphocytic leukemia. J. Exp. Med. 171:559-564.

21. Pegoraro, L., A. Palumbo, J. Erikson, M. Falda, B. Giovanazzo, B. S. Emanuel, G. Rovera, and P. C. Nowell. 1984. A 14;18 and 8;14 chromosome translocation in a cell line derived from an acute B-cell leukemia. Proc. Natl. Acad. Sci. USA. 81:7166-7170.

22. Matsuzaki, H., H. Hata, N. Asou, H. Suzushima, Y. Akahoshi, M. Yo shida, S. Nagakura, T. Ishii, I. Sanada, and K. Takatsuki. 1990. Establishment and characterization of acute B-cell lymphocytic leukemia cell line showing $(8 ; 14)$ and $(14 ; 18)$ chromosome translocation. Acta Haematol. 84:156-161.

23. Gauwerky, C. E., J. Hoxie, P. C. Nowell, and C. M. Croce. 1988. Pre-B- cell leukemia with a $t(8 ; 14)$ and a $t(14 ; 18)$ translocation is preceded by a follicular lymphoma. Oncogene. 2:431-435.

24. Gauwerky, C. E., F. G. Haluska, Y. Tsujimoto, P. C. Nowell, and C. M Croce. 1988. Evolution of B-cell malignancy: pre-B-cell leukemia resulting from MYC activation in a B-cell neoplasm with a rearranged BCL2 gene. Proc. Natl. Acad. Sci. USA. 85:8548-8552.

25. Kiem, H.-P., J. Nourse, D. L. Saltman, K. D. Blume, and M. L. Cleary. 1990. Concurrent activation of c-myc and inactivation of bcl-2 by chromosomal translocation in a lymphoblastic lymphoma cell line. Oncogene. 5:1815-1819.

26. Siegelman, M. H., M. L. Cleary, R. Warnke, and J. Sklar. 1985. Frequent biclonality and Ig gene alterations among B cell lymphomas that show multiple histologic forms. J. Exp. Med. 161:850-863.

27. Carter, M., G. A. M. Neale, and G. R. Kitchingman. 1991. Characterization of immunoglobulin heavy chain genes from an acute leukemia with four rearrangements. Leukemia. 5:668-672.

28. Beishuizen, A., K. Hahlen, A. Hagemeijer, M.-A. J. Verhoeven, H. Hooijkaas, H. J. Adriaansen, I. L. M. Wolvers, E. R. van Wering, and J. J. M. van Dongen. 1991. Multiple rearranged immunoglobulin genes in childhood acute lymphoblastic leukemia of precursor B-cell origin. Leukemia. 5:657-667.

29. Bertolli, L. F., H. Kubagawa, G. V. Borzillo, M. Mayumi, J. T. Prachal, J. F. Kearney, J. R. Durant, and M. D. Cooper. 1987. Analysis with anti-idiotype antibody of a patient with chronic lymphocytic leukemia and a large cell lymphoma (Richter's syndrome). Blood. 70:45-50.

30. Ostrowski, M., M. Minden, C. Wang, and D. Bailey. 1989. Immunophenotypic and gene probe analysis of a case of Richter's syndrome. Am. J. Pathol. 91:215-221.

31. Cleary, M. L., R. Warnke, and J. Sklar. 1984. Monoclonality of lymphoproliferative lesions in cardiac transplant recipients: clonal analysis based on immunoglobulin gene rearrangements. $N$. Engl. J. Med. 310:477-482.

32. Cleary, M. L., and J. Sklar. 1984. Lymphoproliferative disorders in cardiac transplant recipients are multiclonal lymphomas. Lancet. ii:489-493.

33. Vogelstein, B., E. R. Fearon, S. R. Hamiltion, and A. P. Feinberg. 1985. Use of restriction fragment length polymorphism to determine the clonal origin of human tumors. Science (Wash. DC). 227:642-645.

34. Alt, F., N. Rosenberg, S. Lewis, E. Thomas, and D. Baltimore. 1981. Organization and reorganization of immunoglobulin genes in A-MuLV transformed cells: rearrangement of heavy but not light chain genes. Cell. 27:381-390.

35. Bakhshi, A., J. Minowada, A. Arnold, J. Cossman, J. P. Jensen, J. WhangPeng. T. A. Waldmann, and S. J. Korsmeyer. 1983. Lymphoid blast crisis of chronic myelogenous leukemia represents stages in the development of B-cell precursors. N. Engl. J. Med. 309:826-831.

36. Levy, R., S. Levy, M. L. Cleary, W. Carroll, S. Kon, J. Bird, and J. Sklar 1987. Somatic mutation in human B-cell tumors. Immunol. Rev. 96:43-58.

37. Bird, J., N. Galili, M. Link, D. Stites, and J. Sklar. 1988. Continuing rearrangement but absence of somatic hypermutation in immunoglobulin genes of human B-cell precursor leukemia. J. Exp. Med. 168:229-245.

38. Cleary, M. L., N. Galili, M. Trela, R. Levy, and J. Sklar. 1988. Single cell origin of bigenotypic and biphenotypic B-cell proliferations in human follicular lymphomas. J. Exp. Med. 167:582-597. 